\title{
Heterometallic Anilato-Based Layered Magnets
}

\author{
Samia Benmansour and Carlos J. Gómez-García* \\ Departamento de Química Inorgánica, ICMol, Universidad de Valencia, Catedrático José Beltrán 2, \\ 46980 Paterna, Valencia, Spain \\ Email: carlos.gomez@uv.es (C. J. G. G.)
}

\begin{abstract}
In this review, we present the recent use of anilato-based ligands (derivatives of the 3,6-disubstituted-2,5-dihydroxy-1,4-benzoquinone dianion $=\mathrm{C}_{6} \mathrm{O}_{4} \mathrm{X}_{2}{ }^{2-}$ ) to build heterometallic 2D magnets. Among the different metal couples, the $\mathrm{Mn}(\mathrm{II}) \mathrm{Cr}(\mathrm{III})$-containing layers are, by far, the most studied and characterized ones. We will show the structures and properties of the extended families of layered magnets formulated as $A\left[M^{\prime \prime} M^{\prime \prime \prime}\left(C_{6} O_{4} X_{2}\right)_{3}\right] \cdot G$ and $A_{2}\left[M^{\prime} M^{\prime \prime \prime}\left(C_{6} O_{4} X_{2}\right)_{3}\right] \cdot G(A=$ monocation; $X=C l, B r, C N, \cdots ; G$ solvent molecules $)$. We also focus on how it is possible to modulate the magnetic properties of these magnets (ordering temperatures and coercive fields) by simply changing the cation, the $X$ groups, the solvent molecules and the oxidation state of the anilato ligand. Moreover, the tune of the magnetic properties of these layered magnets in a post-synthetic way is also shown.
\end{abstract}

Keywords layered magnets, anilato ligands, heterometallic compounds, magnetic properties, molecule-based magnets

\section{Introduction}

The design, synthesis and characterization of moleculebased magnets has been one of the most active areas in materials chemistry since the discovery of the very first moleculebased magnet: a diethyl-dithio-carbamato Fe(III) complex more than fifty years ago. ${ }^{[1,2]}$ The efforts devoted to this area lead to the preparation of hundreds of molecular magnets. ${ }^{[3]}$ Some of them have critical temperatures above room temperature ${ }^{[4]}$ or combine the magnetic order with a second interesting property as metallic conductivity. ${ }^{[5]}$

Most of these molecule-based magnets have been prepared with simple ligands as cyanide, oxalate or carboxylates. ${ }^{[6]}$ One of the most versatile family of molecule-based magnets is the oxalate-based family formulated as $A\left[M^{\prime \prime} M^{\prime \prime \prime}\left(C_{2} O_{4}\right)_{3}\right](A=$ monocation; $\left.\mathrm{M}^{\prime \prime}=\mathrm{Mn}, \mathrm{Fe}, \mathrm{Co}, \mathrm{Ni}, \mathrm{Cu}, \cdots ; \mathrm{M}^{\prime \prime \prime}=\mathrm{Cr}, \mathrm{Fe}, \cdots\right)$ initially reported by Okawa et al. ${ }^{[7]}$ in 1992 and latter enlarged by other groups. This family of heterometallic magnets may present two different topologies: a 2D honey comb $(6,3)$ lattice ${ }^{[8]}$ and a 3D chiral $(10,3)$ lattice. ${ }^{[9]}$ In both lattices, the change of $M^{11}$ and $\mathrm{M}^{\text {III }}$ leads to a large family of ferro- and ferrimagnets with ordering temperatures of up to $48 \mathrm{~K}^{[10-13]}$ and coercive fields at 2 $\mathrm{K}$ above $1 \mathrm{~T} .{ }^{[14]}$ Albeit, this family presents an important drawback: the oxalate ligand cannot be modified in order to tune the magnetic properties (Scheme 1). This drawback has recently been overcome with the family of anilato-type ligands that present a similar coordination mode (Scheme 1) and give rise to the same topologies than oxalato but can be easily modified. ${ }^{[15,16]}$ Thus, we and others have recently reported the preparation of the first heterometallic anilato-based magnets, formulated as $\mathrm{A}\left[\mathrm{MnCr}\left(\mathrm{C}_{6} \mathrm{O}_{4} \mathrm{X}_{2}\right)_{3}\right] \cdot \mathrm{G}\left(\mathrm{A}=\mathrm{NBu}_{4}{ }^{+}\right.$and $\left[\left(\mathrm{H}_{3} \mathrm{O}\right)(\mathrm{phz})_{3}\right]^{+} ; \mathrm{X}=\mathrm{H}, \mathrm{Cl}, \mathrm{Br}$ and $\mathrm{I} ; \mathrm{G}=\mathrm{H}_{2} \mathrm{O}$ and $\left.\mathrm{CH}_{3} \mathrm{COCH}_{3}\right) .{ }^{[17]}$ This initial work took advantage of the observation, initially made by Lu et al. ${ }^{[18]}$ and later by Shilov et al. ${ }^{[19]}$ that the phenazine molecule perfectly fits the size of the hexagonal cavities formed in the $\left[\mathrm{M}_{2}\left(\mathrm{C}_{6} \mathrm{O}_{4} \mathrm{X}_{2}\right)_{3}\right]^{n-}$ layers (Scheme 1 ), facilitating the crystallization of these, otherwise, difficult to crystallize, layered compounds. Before the work of Lu et al., ${ }^{[18]}$
Scheme 1 Bis-bidentate coordination mode of the oxalato (left) and anilato (center) ligands. The phenazine molecule (right)<smiles></smiles><smiles>[M]Oc1c([X])c2c(O[M])c([X])c1NO2</smiles><smiles>c1ccc2nc3ccccc3nc2c1</smiles>

oxalato

phenazine $(\mathrm{phz})$

only the sodium salt of the homometallic $\left[\mathrm{Mn}_{2}\left(\mathrm{C}_{6} \mathrm{O}_{4} \mathrm{H}_{2}\right)_{3}\right]^{2-}$ layer had been crystallized. ${ }^{[20]}$

The 2013 publication with the first heterometallic anilatobased layers with phenazine as a template agent, also reported the first layered anilato-based structure with $\mathrm{NBu}_{4}{ }^{+}$as cation. ${ }^{[17]}$ Since then, more than thirty different heterometallic $\left[\mathrm{MM}^{\prime}\left(\mathrm{C}_{6} \mathrm{O}_{4} \mathrm{X}_{2}\right)_{3}\right]^{n-}$ layers have been reported with different metal ions, anilato ligands and counter cations (Tables $1-3$ ). Herein, we will revise the structures of these heterometallic layered compounds and their magnetic and electrical properties. These heterometallic layers can be classified into two different families depending on the oxidation state of the metal ions: (i) monoanionic layers formulated as $\left[\mathrm{M}^{\prime \prime} \mathrm{M}^{\prime \prime \prime}\left(\mathrm{C}_{6} \mathrm{O}_{4} \mathrm{X}_{2}\right)_{3}\right]^{-}$and (ii) dianionic layers formulated as $\left[\mathrm{M}^{\prime} \mathrm{M}^{\prime \prime \prime}\left(\mathrm{C}_{6} \mathrm{O}_{4} \mathrm{X}_{2}\right)_{3}\right]^{2-}$. The $\mathrm{M}(\mathrm{II}) \mathrm{M}(\mathrm{III})$ series is by far the largest one and has been reported for three different couples of metals: $\mathrm{Mn}(\mathrm{II}) \mathrm{Cr}(\mathrm{III}), \mathrm{Mn}(\mathrm{II}) \mathrm{Fe}(\mathrm{III})$ and $\mathrm{Fe}(\mathrm{II}) \mathrm{Fe}(\mathrm{III})$. The $\mathrm{M}(\mathrm{I}) \mathrm{M}(\mathrm{III})$ series has only been reported for the couples $\mathrm{Na}(\mathrm{I}) \mathrm{Cr}(\mathrm{III})$ and $\mathrm{K}(\mathrm{I}) \mathrm{Fe}(\mathrm{III}) .{ }^{[21,22]}$ It is less interesting from the magnetic point of view since it does not show magnetic order. Albeit, it may include conducting cations ${ }^{[22]}$ and one of them constitutes the first example of polymorphism in anilato-based coordination polymers. ${ }^{[21]}$

\section{$\mathrm{Mn}$ (II) $\mathrm{Cr}$ (III) Series}

As can be seen in Table 1, most of the reported examples 


\section{Minireview}

Table 1 Structural and magnetic properties of all the reported $\mathrm{A}\left[\mathrm{Mn}^{\text {"I }} \mathrm{Cr}^{\prime \prime \prime}\left(\mathrm{C}_{6} \mathrm{O}_{4} \mathrm{X}_{2}\right)_{3}\right] \cdot \mathrm{G}$ compounds

\begin{tabular}{|c|c|c|c|c|c|c|c|c|}
\hline \# & CCDC & $A^{+}$ & $x$ & $\mathrm{SG}^{a}$ & $\mathrm{P}^{b}$ & $\begin{array}{c}T_{\mathrm{c}} l \\
\mathrm{~K} \\
\end{array}$ & $\begin{array}{c}H_{\mathrm{c}}{ }^{c} / \\
\mathrm{mT}\end{array}$ & Ref \\
\hline 1 & MIRFEA & $\mathrm{H}_{3} \mathrm{O}(\mathrm{phz})_{3}{ }^{+}$ & $\mathrm{Cl}$ & $P 3$ & $E$ & 5.5 & 19.4 & {$\left[\begin{array}{lll}1 & \end{array}\right.$} \\
\hline 2 & MIRFIE & $\mathrm{H}_{3} \mathrm{O}(\mathrm{phz})_{3}^{+}$ & $\mathrm{Br}$ & & $E$ & 6.3 & 34.0 & {$[17$} \\
\hline 3 & MIRFUQ & $\mathrm{NBu}_{4}^{+}$ & $\mathrm{Cl}$ & $C 2 / c$ & A & 5.5 & 11.8 & {$[17$} \\
\hline 4 & HOWHAE & $\mathrm{Fe}\left(\mathrm{sal}_{2} \text {-trien }\right)^{+}$ & $\mathrm{Cl}$ & $C 222_{1}$ & A & 10.0 & 35 & {$[29$} \\
\hline 5 & HOWHEI & $\mathrm{Fe}\left(4-\mathrm{OH}-\text { sal }_{2} \text { trien }\right)^{+}$ & $\mathrm{Cl}$ & & $A$ & 10.4 & 87 & {$[2 \varsigma$} \\
\hline 6 & HOWHIM & $\mathrm{Fe}\left(\mathrm{sal}_{2} \text {-epe }\right)^{+}$ & $\mathrm{Br}$ & $P 21 / c$ & $A$ & 10.2 & 10 & {$[29$} \\
\hline 7 & HOWHOS & $\mathrm{Fe}\left(5-\mathrm{Cl}-\mathrm{sal}_{2} \text {-trien }\right)^{+}$ & $\mathrm{Br}$ & $P 21 / c$ & A & 9.8 & 66 & {$[2$} \\
\hline 8 & MUMKUC & {$\left[\mathrm{Fe}\left(\mathrm{acac}_{2} \text {-trien }\right)\right]^{+}$} & $\mathrm{Cl}$ & $C 2 / c$ & $A$ & 10.8 & 65 & {$[2 \varepsilon$} \\
\hline 9 & MUMLAJ & {$\left[\mathrm{Fe}\left(\mathrm{acac}_{2} \text {-trien }\right)\right]^{+}$} & $\mathrm{Br}$ & $C 2 / c$ & A & 11.1 & 77 & {$[28$} \\
\hline 0 & MUM & {$\left[\mathrm{Ga}\left(\mathrm{acac}_{2}\right.\right.$} & $\mathrm{Br}$ & $C 2 / c$ & A & 11.6 & 72 & {$[28$} \\
\hline 1 & SEPLAD & $\mathrm{MIe}_{2} \mathrm{NH}_{2}$ & $\mathrm{Br}$ & $P-3$ & $A$ & 7.9 & 90 & {$[27$} \\
\hline 2 & SEPLEH & $\mathrm{Et}_{2} \mathrm{~N}$ & $\mathrm{Br}$ & $P-3$ & A & 8.9 & 100 & {$[27$} \\
\hline 3 & SEQCID & $\mathrm{Et}_{3} \mathrm{~N}$ & $\mathrm{Cl}$ & $P-31 c$ & A & 8.0 & 150 & {$[27$} \\
\hline & SEPROX & $\mathrm{Et}(i-\mathrm{Pr})_{2} \mathrm{NH}^{+}$ & $\mathrm{Br}$ & $P-31 c$ & $A$ & 9.0 & $4^{\mathrm{d}}$ & {$[2$} \\
\hline 5 & HORMAF & $\mathrm{NBu}_{4}^{+}$ & $\mathrm{Br}$ & $P 2_{1}$ & $E$ & 9.5 & 33 & {$[23$} \\
\hline 16 & FOJYAH & $\mathrm{NBu}_{4}{ }^{+}$ & $\mathrm{Cl}$ & $P 2_{1}$ & E & 7.0 & 7.6 & {$[2$} \\
\hline 7 & FOJYEL & $\mathrm{NBu}_{4}{ }^{+}$ & $\mathrm{Br}$ & $P 2_{1}$ & E & 6.7 & 10 & {$[2$} \\
\hline 18 & FOJ & & $\mathrm{Cl}$ & $P 2_{1}$ & $E$ & 6.8 & 5.0 & {$[2$} \\
\hline 19 & FOJZAI & $\mathrm{NBu}_{4}{ }^{+}$ & $\mathrm{Br}$ & $P 2_{1}$ & E & 6.7 & 20 & {$[2$} \\
\hline 20 & - & $\mathrm{H}_{3} \mathrm{O}^{+}$ & $\mathrm{Cl}$ & $P 21 / n$ & $E$ & 10.5 & 90 & [3 \\
\hline 21 & - & $\mathrm{H}_{3} \mathrm{O}^{+}$ & $\mathrm{Br}$ & $P 21 / n$ & $E$ & $3.6^{\mathrm{e}}$ & $210^{\mathrm{e}}$ & {$[3$} \\
\hline
\end{tabular}

${ }^{a}$ Space group. ${ }^{b}$ Packing: $\mathrm{A}=$ alternating, $\mathrm{E}=$ eclipsed. ${ }^{c}$ Coercive field at $2 \mathrm{~K} .{ }^{d} \mathrm{~A}$ solvated phase of this compound is metamagnetic with a critical field of $490 \mathrm{mT}$ at $2 \mathrm{~K}$. ${ }^{e}$ This compound is metamagnetic with a $T_{\mathrm{N}}$ of $3.6 \mathrm{~K}$ at low fields and a critical field of $210 \mathrm{mT}$ at $2 \mathrm{~K}$.

Table 2 Structural and magnetic properties of all the reported $\mathrm{A}\left[\mathrm{Mn}^{\prime \prime} \mathrm{Fe}^{\prime \prime \prime}\left(\mathrm{C}_{6} \mathrm{O}_{4} \mathrm{X}_{2}\right)_{3}\right] \cdot \mathrm{G}$ and $\mathrm{A}\left[\mathrm{Fe}^{\prime \prime} \mathrm{Fe}^{\prime \prime \prime}\left(\mathrm{C}_{6} \mathrm{O}_{4} \mathrm{X}_{2}\right)_{3}\right] \cdot \mathrm{G}$ compounds

\begin{tabular}{|c|c|c|c|c|c|c|c|}
\hline \# & CCDC & $\mathrm{A}^{+}$ & $x$ & $S G^{a}$ & $\mathrm{M}^{\prime \prime} \mathrm{M}^{\mathrm{III}} T_{\mathrm{c}} / \mathrm{K}$ & $\begin{array}{l}H_{\mathrm{c}}{ }^{b} / \\
\mathrm{mT}\end{array}$ & Ref. \\
\hline 22 & MIRFOK & $\mathrm{H}_{3} \mathrm{O}(\mathrm{phz})_{3}{ }^{+}$ & $\mathrm{Br}$ & $P-31 m$ & $\mathrm{MnFe}-$ & - & [17] \\
\hline 23 & QEFPOJ & $\mathrm{H}_{3} \mathrm{O}(\mathrm{phz})_{3}{ }^{+}$ & $\mathrm{Cl}$ & $P-31 m$ & FeFe 2.4 & 1.0 & [31] \\
\hline 24 & QEFPID & $\mathrm{H}_{3} \mathrm{O}(\mathrm{phz})_{3}{ }^{+}$ & $\mathrm{Br}$ & $P-31 m$ & $\mathrm{FeFe} \quad 2.1$ & 1.0 & [31] \\
\hline 25 & NIHJEW & $\mathrm{C}\left(\mathrm{N}_{2} \mathrm{H}_{3}\right)_{3}{ }^{+}$ & $\mathrm{Cl} / \mathrm{CN}$ & P3 & FeFe 4.0 & 6 & [32] \\
\hline
\end{tabular}

${ }^{a}$ Space group. ${ }^{b}$ Coercive field at $2 \mathrm{~K}$.

Table 3 Structural properties of all the reported $\mathrm{A}_{2}\left[\mathrm{M}^{\prime} \mathrm{M}^{\prime \prime \prime}\left(\mathrm{C}_{6} \mathrm{O}_{4} \mathrm{X}_{2}\right)_{3}\right] \cdot \mathrm{G}$ compounds

\begin{tabular}{|c|c|c|c|c|c|}
\hline \# & CCDC & $\mathrm{A}^{+}$ & $x$ & $\mathrm{SG}^{a}$ & MIMIII Ref. \\
\hline 26 & PALXUY & S-TM-ET/PPh ${ }^{4+}$ & $\mathrm{Cl}$ & $P 1$ & $\mathrm{KFe} \quad$ [22] \\
\hline 27 & PALYAF & R-TM-ET/PPh ${ }^{4+}$ & $\mathrm{Cl}$ & $P 1$ & $\mathrm{KFe} \quad$ [22] \\
\hline 28 & PALYEJ & rac-TM-ET/PPh ${ }^{4+}$ & $\mathrm{Cl}$ & $P-1$ & $\mathrm{KFe}$ \\
\hline 29 & QUJJIQ & $\mathrm{PBu}_{3} \mathrm{Me}^{+}$ & $\mathrm{Br}$ & $P 2_{1}$ & $\mathrm{NaCr}$ [21] \\
\hline 30 & QUJJOW & $\mathrm{PPh}_{3} \mathrm{Et}^{+}$ & $\mathrm{Cl}$ & $P 2_{1}$ & $\mathrm{KFe}$ [21] \\
\hline 31 & - & $\mathrm{NBu}_{3} \mathrm{Me}^{+}$ & $\mathrm{Br}$ & & $\mathrm{NaCr}$ [21] \\
\hline 32 & QUJJUC & $\mathrm{NBu}_{3} \mathrm{Me}^{+}$ & $\mathrm{Br}$ & $1-43 d$ & $\mathrm{NaCr}$ [21] \\
\hline
\end{tabular}

${ }^{a}$ Space group.

of the $\mathrm{M}(\mathrm{II}) \mathrm{M}(\mathrm{III})$ series contain $\mathrm{Mn}(\mathrm{II})$ and $\mathrm{Cr}(\mathrm{III})$ as metal ions.

The few $\mathrm{Mn}(\mathrm{II}) \mathrm{Fe}(\mathrm{III})$ and $\mathrm{Fe}(\mathrm{II}) \mathrm{Fe}(\mathrm{III})$ examples are shown in Table 2. NOTE: Although the $\mathrm{Fe}(\mathrm{II}) \mathrm{Fe}(\mathrm{III})$ derivatives are not heterometallic, we include them here because they presen similar magnetic properties to the heterometallic ones, given the different oxidation state and, therefore, the different spin ground state of both metal ions.

All the reported $\mathrm{M}(\mathrm{II}) \mathrm{M}(\mathrm{III})$ derivatives show the typical 2D honeycomb structure, where the $M(I I)$ and $M(I I I)$ ions alternate in the vertex and the anilato ligands form the sides of the hexagons (Figure 1).

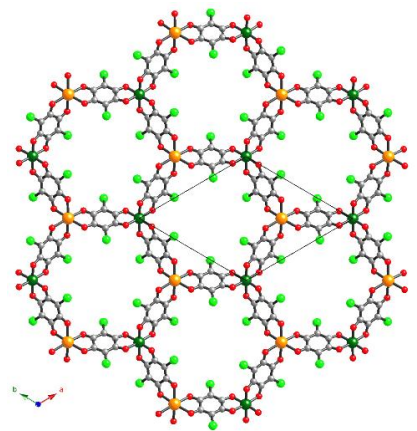

Figure 1 Honey comb structure of the $\left[\mathrm{M}^{\prime \prime} \mathrm{M}^{\prime \prime \prime}\left(\mathrm{C}_{6} \mathrm{O}_{4} \mathrm{X}_{2}\right)_{3}\right]^{-}$layers.

Both metal ions show an octahedral coordination environment (except is a few cases, see below) and appear coordinated to three chelating anilato ligands (Figure 2, left).
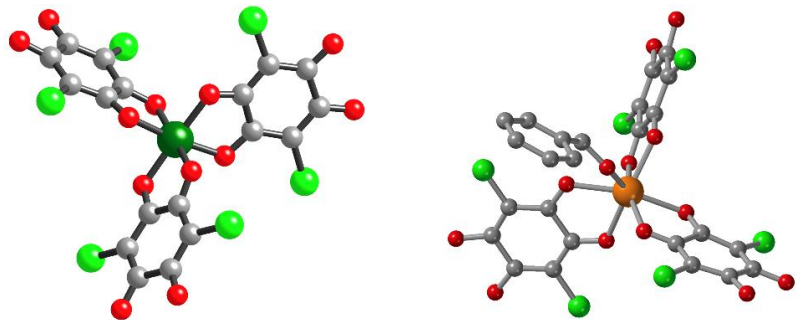

Figure 2 (Left) Tris-quelated coordination environment of the metal ions in the $\left[\mathrm{M}^{\prime \prime} \mathrm{M}^{\prime \prime \prime}\left(\mathrm{C}_{6} \mathrm{O}_{4} \mathrm{X}_{2}\right)_{3}\right]^{-}$layers. (Right) Hepta-coordination of the $\mathrm{Mn}(\mathrm{II})$ centers in compounds 16-19.

The tris(anilato)metallate(III) complexes show alternating $\Delta$ and $\Lambda$ configurations, giving rise to the hexagonal layers. The $\left[\mathrm{M}^{\prime \prime} \mathrm{M}^{\mathrm{III}}\left(\mathrm{C}_{6} \mathrm{O}_{4} \mathrm{X}_{2}\right)_{3}\right]^{-}$layers alternate with layers containing the cations $\left(\mathrm{A}^{+}\right)$(Figure 3 ). However, there are some exceptions in compounds 8-13, where the cations are located inside the hexagonal cavities of the honey comb layers and in compound 14, that shows double anionic layers alternating with simple cationic ones.

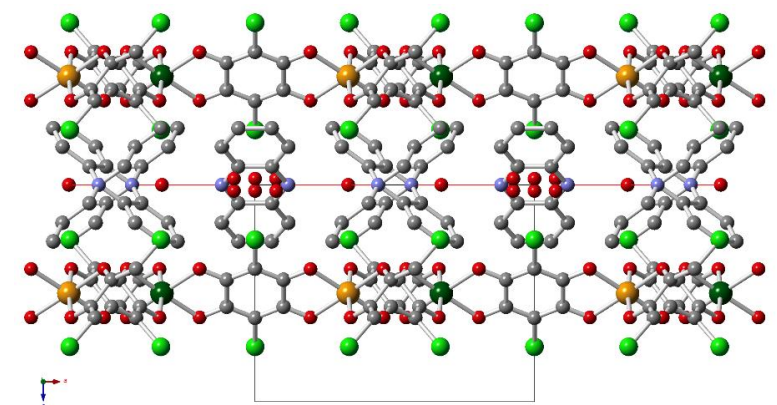

Figure 3 Alternating cationic and anionic layers in the series of compounds $A\left[M^{\prime \prime} M^{\prime \prime \prime}\left(\mathrm{C}_{6} \mathrm{O}_{4} \mathrm{X}_{2}\right)_{3}\right]$.

The disposition of the anionic layers can be eclipsed or alternated (Figure 4). The first disposition generates hexagonal channels perpendicular to the layers and is only observed in the two examples with the $\left[\left(\mathrm{H}_{3} \mathrm{O}\right)(\mathrm{phz})_{3}\right]^{+}$cation $(1$ and 2$),{ }^{[17]}$ in five recently reported compounds with $\mathrm{NBu}_{4}{ }^{+}$cations and benzene 

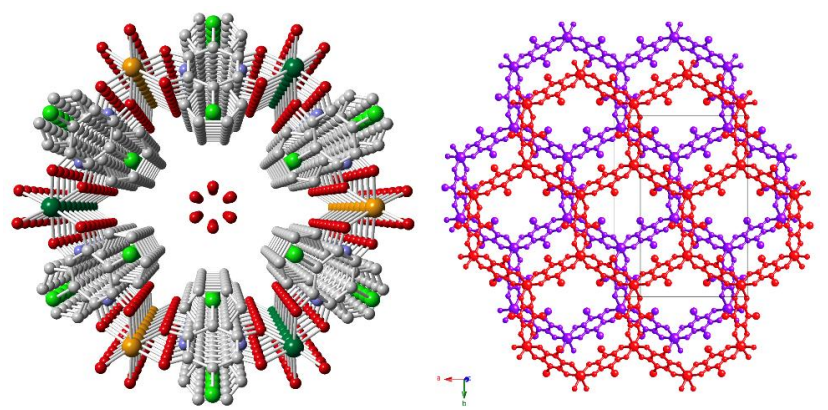

Figure 4 (left) Eclipsed packing and (right) alternating packing of the $\left[M^{\prime \prime} M^{\prime \prime \prime}\left(\mathrm{C}_{6} \mathrm{O}_{4} \mathrm{X}_{2}\right)_{3}\right]^{-}$layers.

derivatives solvent molecules (15-19) and in a couple of compounds with $\mathrm{H}_{3} \mathrm{O}^{+}$as cation (20 and 21) (Figure 4, left). ${ }^{[3,24]}$ Interestingly, the first reported structure with the $\mathrm{NBu}_{4}{ }^{+}$cation showed an alternating disposition of the anionic layers (Figure 4 , right). ${ }^{[17]}$ It seems that the benzene-derivative solvent molecules may play a template role favouring the formation of the eclipsed packing. The crystallization solvent molecules $\left(\mathrm{H}_{2} \mathrm{O}\right.$, $\mathrm{CH}_{3} \mathrm{COCH}_{3}, \mathrm{PhBr}, \mathrm{PhCHO}, \mathrm{C}_{6} \mathrm{H}_{6}, \mathrm{CH}_{3} \mathrm{CN}, \mathrm{CH}_{3} \mathrm{OH}, \mathrm{CH}_{2} \mathrm{Cl}_{2}, \cdots$ ) are located in these hexagonal channels (Figure 4, left) or in the hexagonal cavities when the layers are alternated.

Finally, it is worth to mention that, although the anionic layers are formulated as $\left[\mathrm{MnCr}\left(\mathrm{C}_{6} \mathrm{O}_{4} \mathrm{X}_{2}\right)_{3}\right]^{-}(\mathrm{X}=\mathrm{Cl}$ or $\mathrm{Br})$, in compounds 1 and $16-19$ the $\mathrm{Mn}(\mathrm{II})$ ion is additionally coordinated to a seventh oxygen atom (from a $\mathrm{H}_{2} \mathrm{O}$ molecule in 1 and from a $\mathrm{PhCHO}$ molecule in 16-19, Figure 2, right). This hepta-coordination has only been observed for $\mathrm{Mn}(\mathrm{II})$ and may be attributed to the large size of this ion.

From the magnetic point of view, all the $\mathrm{Mn}(\mathrm{II}) \mathrm{Cr}(\mathrm{III}) \mathrm{com}-$ pounds are ferrimagnets since the $S=5 / 2 \mathrm{Mn}$ (II) ions are antiferromagnetically coupled to the $S=3 / 2 \mathrm{Cr}$ (III) ions, resulting in a long range ferrimagnetic ordering. The ferrimagnetic couplings are clearly shown by the decrease of the $\chi_{\mathrm{m}} T$ product when the samples are cooled and by the presence of a minimum at low temperatures with a sharp increase at lower temperatures (Figure 5, top). The critical temperatures, determined
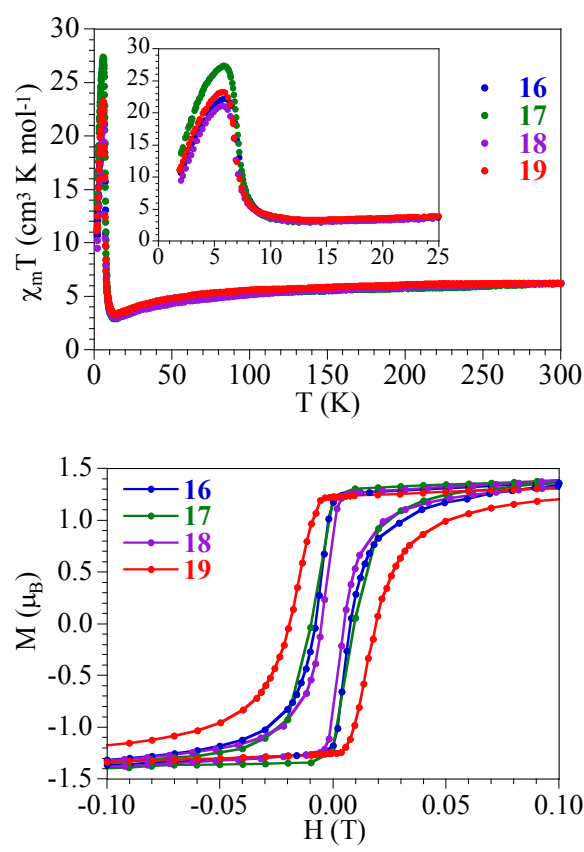

Figure 5 (Top) Thermal variation of the $\chi_{\mathrm{m}} \mathrm{T}$ product for compounds 16-19. (Bottom) Hysteresis cycles at $2 \mathrm{~K}$ of compounds 16-19. with $\mathrm{AC}$ susceptibility measurements, range from 5.5 to $11.6 \mathrm{~K}$ and the coercive fields at $2 \mathrm{~K}$ range from 4 to $150 \mathrm{mT}$ (Table 1 , Figure 5, bottom).

An interesting possibility offered by these materials is the fine tuning of the ordering temperatures by simply changing the $X$ group in the anilato ligand. This capacity was evidenced in the series of compounds $\mathrm{NBu}_{4}\left[\mathrm{MnCr}\left(\mathrm{C}_{6} \mathrm{O}_{4} \mathrm{X}_{2}\right)_{3}\right] \cdot \mathrm{G}$, where the ordering temperature can be modulated as a function of the electronegativity of $\mathrm{X}\left(T_{\mathrm{c}}=5.5,6.3,8.2\right.$, and $11.0 \mathrm{~K}$ for $\mathrm{X}=\mathrm{Cl}$, $\mathrm{Br}$, I, and $\mathrm{H}$, respectively, Figure 6). ${ }^{[2]}$
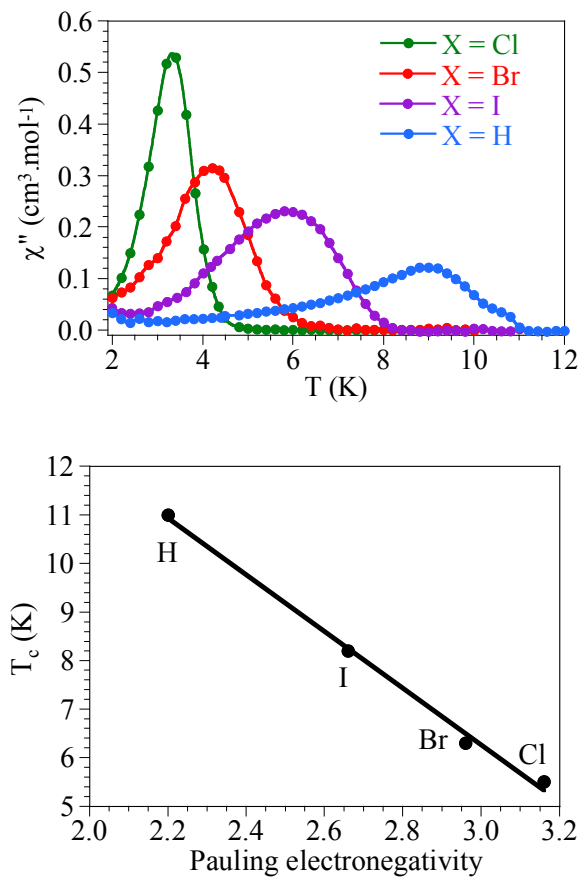

Figure 6 (Top) AC susceptibility of the series of compounds $\mathrm{NBu}_{4}\left[\mathrm{MnCr}\left(\mathrm{C}_{6} \mathrm{O}_{4} \mathrm{X}_{2}\right)_{3}\right](\mathrm{X}=\mathrm{H}, \mathrm{Cl}, \mathrm{Br}$ and I). (Bottom) Variation of $T_{\mathrm{c}}$ with the electronegativity of the $\mathrm{X}$ group in the same series.

A second way to tune the ordering temperatures is provided by the possibility to reduce (chemically or electrochemically) the anilato ligands to form the corresponding semiquinone radical form. This strategy has already given a very interesting example of increase of the ordering temperature from 10 to $36 \mathrm{~K}$ by electrochemical reduction. ${ }^{[25]}$

Although in this family of layered ferrimagnets the ordering temperature mainly depends on the $\mathrm{Mn}-\mathrm{Cr}$ magnetic coupling through the anilato bridge (that can be controlled with $X$ and with the reduction of the ligand), there are other ways to fine tune the magnetic properties of this family of layered magnets. As can be seen in Table 1, the presence of solvent molecules in the hexagonal cavities (either coordinated or not to the Mn(II) ion) and in the hexagonal channels formed when the packing is eclipsed, may also play an important role in $T_{\mathrm{c}}$. A close look at the $T_{\mathrm{c}}$ values for $\mathrm{X}=\mathrm{Cl}$ shows that, when there is an additional ligand $\left(\mathrm{H}_{2} \mathrm{O}\right.$ or $\left.\mathrm{PhCHO}\right)$ coordinated to the $\mathrm{Mn}(\mathrm{II})$ centre (as in compounds 1,16 and 18$), T_{\mathrm{c}}$ is lower $(5.5,7.0$ and $6.8 \mathrm{~K}$, respectively) than in the other compounds (Table 1). For $X=\mathrm{Br}$, we observe the same trend in compounds 17 and 19 that also present a $\mathrm{PhCHO}$ molecule coordinated to the $\mathrm{Mn}$ (II) center. The lower $T_{\mathrm{c}}$ value observed in compound $\mathbf{2}$ (where no additional ligand is coordinated to the $\mathrm{Mn}(\mathrm{II})$ center) may be attributed to: (i) the presence of the $\left[\left(\mathrm{H}_{3} \mathrm{O}\right)(\mathrm{phz})_{3}\right]^{+}$cation (that shows a strong $\Pi-\pi$ stacking interaction with the anilato ligand and, therefore, modifies its electron density); (ii) to a lack of solvent 
molecules in the structure. In fact, the presence/absence of solvent molecules represents an additional way to tune the magnetic properties. This role of the solvent molecules has been very recently demonstrated in a couple of series of isostructural compounds formulated as $\mathrm{NBu}_{4}[\mathrm{MnCr}$ $\left.\left(\mathrm{C}_{6} \mathrm{O}_{4} \mathrm{Cl}_{2}\right)_{3}\right] \cdot n \mathrm{PhX}$ and $\mathrm{NBu}_{4}\left[\mathrm{MnCr}\left(\mathrm{C}_{6} \mathrm{O}_{4} \mathrm{Br}_{2}\right)_{3}\right] \cdot n \mathrm{PhX}(n=1,2$; $\mathrm{X}=\mathrm{Cl}, \mathrm{Br}, \mathrm{I}, \mathrm{CH}_{3}, \mathrm{CN}$ and $\mathrm{NO}_{2}$ ), where the insertion, removal and exchange of the solvent molecules leads to changes in $T_{\mathrm{c}}{ }^{[23,26]}$ This solvent exchange and/or removal results in a change of the ordering temperatures and constitutes an additional post-synthetic and easy way to modulate the ordering temperatures.

Furthermore, in a few cases, the ferrimagnetic layers present a weak antiferromagnetic inter-layer coupling leading to a metamagnetic behaviour, as in compounds 14 and 21 , where the antiferromagnetic inter-layer coupling can be overcome by the application of a moderate field (Figure 7).
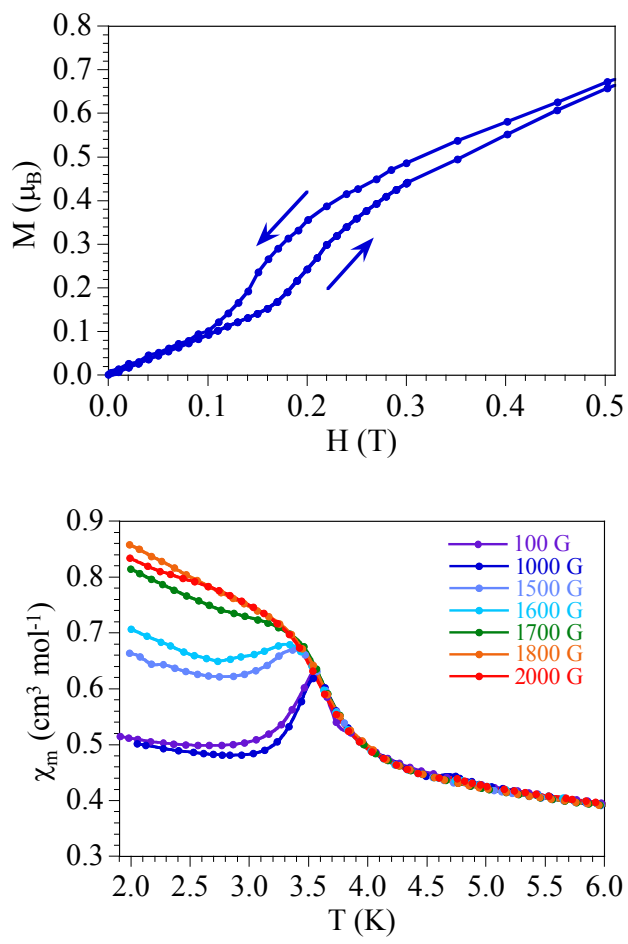

Figure 7 (Top) Magnetization of compound 20 showing the metamagnetic transition at ca. 0.2 T. (Bottom) Thermal variation of $\chi_{\mathrm{m}}$ for compound $\mathbf{2 0}$ with different magnetic fields.

Additionally, in some cases, the $\mathrm{A}^{+}$cations also provide interesting magnetic properties. Thus, the $A^{+}$cations in compounds $\mathbf{4 - 9}$ are typical spin crossover (SCO) cations, although their confinement in between the layers or inside the hexagonal cavities precluded the $\mathrm{SCO}$, at least in these examples. Proton conductivity is another interesting additional property that can be supplied by the cations, as in compounds $11-14$, that show proton conductivities in the range $2.3 \times 10^{-6}$ and $2.4 \times 10^{-5} \mathrm{~S} / \mathrm{cm}$ at $70{ }^{\circ} \mathrm{C}$ and $95 \%$ relative humidity, with activation energies of ca. $0.2 \mathrm{eV}^{[27]}$

Furthermore, compounds $\mathbf{4}$ and $\mathbf{8}-\mathbf{1 0}$ have been exfoliated in thin layers with heights down to $2 \mathrm{~nm}$, introducing novel possibilities of those magnetic materials. ${ }^{[28]}$

\section{Other M(II)M(III) Derivatives}

As mentioned above, there are also a few examples of $\mathrm{Mn}(\mathrm{II}) \mathrm{Fe}(\mathrm{III})$ and $\mathrm{Fe}(\mathrm{II}) \mathrm{Fe}(\mathrm{III})$ reported compounds (Table 2). The only known Mn(II)Fe(III) derivative was also described in the original report with the first heterometallic examples. ${ }^{[17]}$ The magnetic properties of the MnFe derivative show, as expected, an antiferromagnetic $\mathrm{Mn}-\mathrm{Fe}$ coupling but now both ions present the same $S=5 / 2$ spin ground state and this compound does not show any long range order. As observed in all the reported examples with the cation $\left[\left(\mathrm{H}_{3} \mathrm{O}\right)(\mathrm{phz})_{3}\right]^{+}$, the packing of the anionic layers is also eclipsed.

The three reported $\mathrm{Fe}(\mathrm{II}) \mathrm{Fe}(\mathrm{III})$ examples are more interesting since they show ferrimagnetic order with ordering temperatures in the range $2.1-4.0 \mathrm{~K}$ and simultaneously they present a semiconducting behaviour with room temperature conductivities in the range $3 \times 10^{-2}$ to $2 \times 10^{-3} \mathrm{~S} / \mathrm{cm}$ (Figure 8 , top). ${ }^{[31,32]}$ This electrical conductivity is attributed to the mixed valence state of the $\mathrm{Fe}(\mathrm{II}) / \mathrm{Fe}(\mathrm{III})$ layer. Besides the simultaneous presence of magnetic ordering and conducting properties two of the $\mathrm{Fe}(\mathrm{II}) \mathrm{Fe}$ (III) derivatives have been delaminated in thin films of only a few monolayers (Figure 8, bottom). The packing of the layers is also eclipsed in all cases. In compounds 23 and 24, this eclipsed packing is due to the presence of the $\left[\left(\mathrm{H}_{3} \mathrm{O}\right)(\mathrm{phz})_{3}\right]^{+}$cations, whereas it is attributed to the presence of some $\mathrm{H}$-bonds between the $\mathrm{C}\left(\mathrm{N}_{2} \mathrm{H}_{3}\right)^{3+}$ cations and the anionic layers in compound 25. ${ }^{[32]}$
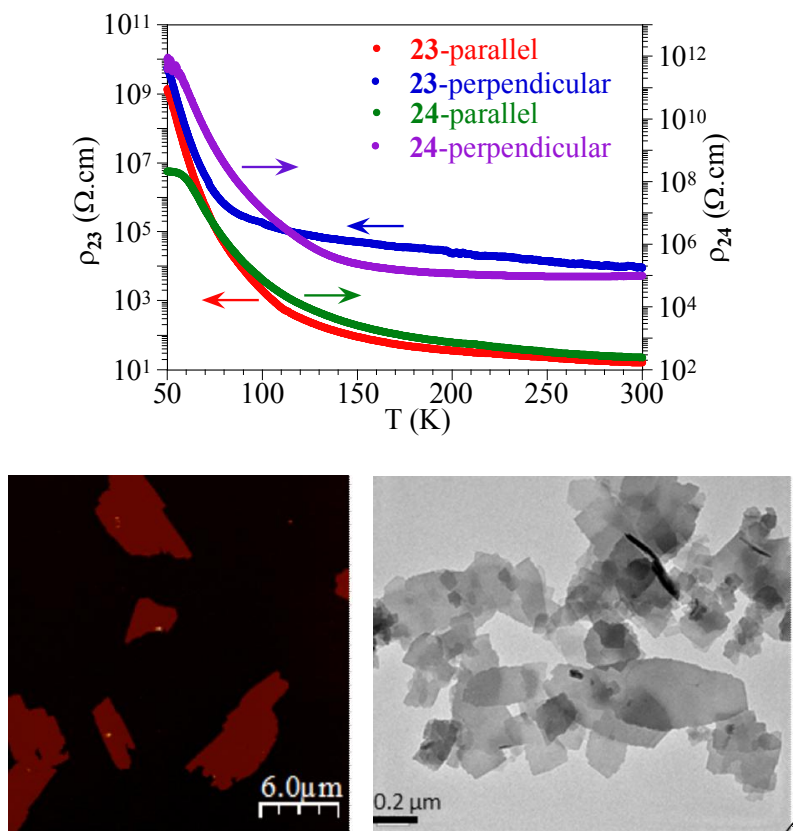

Figure 8 (Up) DC electrical conductivity of compounds $\mathbf{2 3}$ and 24. (Bottom) Nanoflakes of compounds 23 (left) AFM image (thickness $=7 \mathrm{~nm}$ ) and 24 (right) HR-TEM image.

\section{M(I)M(III) Derivatives}

The second series of heterometallic anilato-based layered compounds can be formulated as $\mathrm{A}_{2}\left[\mathrm{M}^{\prime} \mathrm{M}^{\prime \prime \prime}\left(\mathrm{C}_{6} \mathrm{O}_{4} \mathrm{X}_{2}\right)_{3}\right] \cdot \mathrm{G}$ and has only been reported for two couples: $\mathrm{Na}(\mathrm{I}) \mathrm{Cr}(\mathrm{III})$ and $\mathrm{K}(\mathrm{I}) \mathrm{Fe}(\mathrm{III})$ (Table 3). ${ }^{[21,22]}$

The structure of these heterometallic $\mathrm{M}^{\prime} \mathrm{M}^{\text {III }}$ compounds is very similar to that observed in the $\mathrm{M}^{\prime \prime} \mathrm{M}^{\prime \prime \prime}$ series. They also present alternating cationic and honey comb anionic layers (Figure 9, top). The main difference is the shape of the hexagonal cavities since they are slightly irregular in the $M^{\prime} M^{\prime \prime \prime}$ series as shown by the different dimensions of the diagonals of the hexagons and the $M^{\prime}-M^{\prime \prime \prime}-M^{\prime}$ and $M^{\prime \prime \prime}-M^{\prime}-M^{\prime \prime \prime}$ angles (Figure 9, bottom). These differences are attributed to the larger size of the $\mathrm{M}^{\prime}$ cations compared to the $\mathrm{M}^{\text {III }}$ ones. 


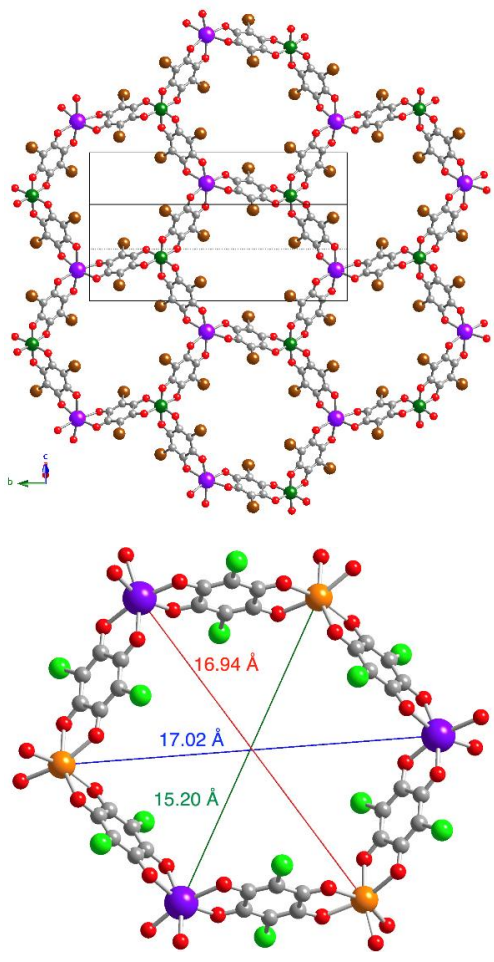

Figure 9 (Top) A $\left[\mathrm{NaCr}\left(\mathrm{C}_{6} \mathrm{O}_{4} \mathrm{Br}_{2}\right)_{3}\right]^{2-}$ layer in compound 29. (Bottom) Detail of one hexagonal cavity in compound 30. Colour code: $\mathrm{C}=$ grey, $\mathrm{O}=$ red, $\mathrm{Cl}=$ light green, $\mathrm{Br}=$ brown, $\mathrm{Cr}=$ dark green, $\mathrm{Fe}=$ orange, $\mathrm{K}=$ purple.

As expected, these compounds are paramagnetic and their magnetic properties correspond to those of the M(III) cations, since the $M(I)$ cations are diamagnetic and isolate the $M(I I I)$ ions from the magnetic point of view. In some of these compounds, the cationic layers show conducting properties as in compounds 26-28, which are semiconductors with room temperature conductivities of $\mathrm{ca} .3 \times 10^{-4} \mathrm{~S} / \mathrm{cm} .{ }^{[22]}$

Another interesting finding in the $\mathrm{M}^{\prime} \mathrm{M}^{\mathrm{III}}$ series is the existence of polymorphism between compounds $\mathbf{3 1}$ and $\mathbf{3 2}$. Thus, compound 31 is the $2 \mathrm{D}$ polymorph of compound 32 , which presents a 3D structure formed by two interpenetrated chiral 10,3-gon lattices (Figure 10).

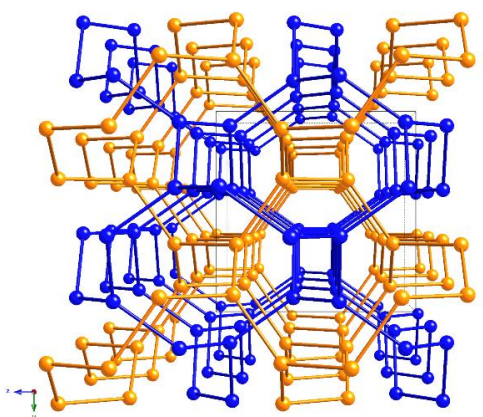

Figure $103 \mathrm{D}$ structure of compound 32 showing the two interpenetrated $\left[\mathrm{NaCr}\left(\mathrm{C}_{6} \mathrm{O}_{4} \mathrm{Br}_{2}\right)_{3}\right]^{2-}$ lattices (only the positions of the metal ions are shown). The lines linking the metal ions represent the anilato bridges.

\section{Conclusions and Perspectives}

The design and synthesis of heterometallic anilato-based compounds have proven to be a successful strategy to prepare new molecule-based magnets and multifunctional molecular materials. The large stability of these heterometallic lattices and their anionic character have allowed the synthesis of many molecular magnets presenting, in some cases, additional properties as electrical conductivity, proton conductivity, solvent exchange, etc.

The possibilities opened by these series of magnets are enormous. Many other cations with other interesting properties as single molecule magnets (SMM), luminescence, non linear optic properties, SCO, and so on, can be intercalated in between the heterometallic layers to construct multifunctional magnets.

The possibility to reduce (chemically or electrochemically) the anilato ligands to form the corresponding semiquinone radical form constitutes a very promising research line in these materials and is expected to yield layered magnets with very high ordering temperatures, as already observed in other homometallic anilato based magnets.

\section{Acknowledgement}

We thank the Spanish MINECO (project CTQ2017-87201-P AEI/FEDER, UE) and the Generalidad Valenciana (project Prometeo/2019/076) for financial support.

\section{Author Contributions}

Both authors have contributed to the writing and revision of the manuscript.

\section{Conflict of Interest}

The authors declare no conflict of interest.

Copyright (c) 2020 Samia Benmansour and Carlos J. GómezGarcía. This article is an open access article distributed under the terms and conditions of the Creative Commons Attribution (CC BY) license (http://creativecommons.org/licenses/by/4.0/). The use, distribution or reproduction in other forums is permitted, provided the original author(s) or licensor are credited and that the original publication in this journal is cited, in accordance with accepted academic practice. No use, distribution or reproduction is permitted which does not comply with these terms.

\section{References}

[1] Wickman, H. H.; Trozzolo, A. M.; Williams, H. J.; Hull, G. W.; Merritt, F. R. Phys. Rev. 1967, 155, 563.

[2] Hoskins, B. F.; White, A. H. J. Chem. Soc. A 1970, 1668.

[3] Kahn, O. Molecular Magnetism, VCH Publishers, USA, 1993.

[4] Ferlay, S.; Mallah, T.; Ouahes, R.; Veillet, P.; Verdaguer, M. Nature 1995, 378, 701.

[5] Coronado, E.; Galán-Mascarós, J. R.; Gómez-García, C. J.; Laukhin, V. Nature 2000, 408, 447.

[6] Zheng, Y.; Zheng, Z.; Chen, X. Coord. Chem. Rev. 2014, 258-259, 1.

[7] Tamaki, H.; Zhong, Z. J.; Matsumoto, N.; Kida, S.; Koikawa, M.; Achiwa, N.; Hashimoto, Y.; Okawa, H. J. Am. Chem. Soc. 1992, $114,6974$.

[8] Atovmyan, L. O.; Shilov, G. V.; Lyubovskaya, R. N.; Zhilyaeva, E. I.; Ovanesyan, N. S.; Pirumova, S. I.; Gusakovskaya, I. G.; Morozov, Y. G. Jetp Lett. 1993, 58, 766.

[9] Coronado, E.; Galan-Mascaros, J. R.; Gómez-García, C. J.; Martínez-Agudo, J. M. Inorg. Chem. 2001, 40, 113.

[10] Mathoniere, C.; Nuttall, C. J.; Carling, S. G.; Day, P. Inorg. Chem. 1996, 35, 1201.

[11] Clemente-Leon, M.; Coronado, E.; Galán-Mascarós, J. R.; GómezGarcía, C. J. Chem. Commun. 1997, 1727.

[12] Coronado, E.; Clemente-León, M.; Galán-Mascarós, J. R.; Giménez-Saiz, C.; Gómez-García, C. J.; Martínez-Ferrero, E. J. Chem. Soc., Dalton Trans. 2000, 3955. 
[13] Coronado, E.; Galán-Mascarós, J. R.; Gómez-García, C. J.; Martínez-Agudo, J. M.; Martínez-Ferrero, E.; Waerenborgh, J. C.; Almeida, M. J. Solid State Chem. 2001, 159, 391.

[14] Coronado, E.; Galán-Mascarós, J. R.; Gómez-García, C. J.; Martínez-Agudo, J. M. Adv. Mater. 1999, 11, 558.

[15] Mercuri, M. L.; Congiu, F.; Concas, G.; Sahadevan, S. A. Magnetochemistry 2017, 3, 17.

[16] Kitagawa, S.; Kawata, S. Coord. Chem. Rev. 2002, 224, 11.

[17] Atzori, M.; Benmansour, S.; Mínguez Espallargas, G.; ClementeLeón, M.; Abhervé, A.; Gómez-Claramunt, P.; Coronado, E.; Artizzu, F.; Sessini, E.; Deplano, P.; Serpe, A.; Mercuri, M. L.; Gómez García, C. J. Inorg. Chem. 2013, 52, 10031.

[18] Luo, T.; Liu, Y.; Tsai, H.; Su, C.; Ueng, C.; Lu, K. Eur. J. Inorg. Chem. 2004, 4253.

[19] Shilov, G. V.; Nikitina, Z. K.; Ovanesyan, N. S.; Aldoshin, S. M.; Makhaev, V. D. Russ. Chem. Bull. 2011, 60, 1209.

[20] Weiss, A.; Riegler, E.; Robl, C. Z. Naturforsch. B: Chem. Sci. 1986, 41, 1501.

[21] Benmansour, S.; Vallés-García, C.; Gómez-Claramunt, P.; Mínguez Espallargas, G.; Gómez-García, C. J. Inorg. Chem. 2015, $54,5410$.

[22] Atzori, M.; Pop, F.; Auban-Senzier, P.; Clérac, R.; Canadell, E.; Mercuri, M. L.; Avarvari, N. Inorg. Chem. 2015, 54, 3643.

[23] Martínez-Hernández, C.; Gómez-Claramunt, P.; Benmansour, S.; Gómez-García, C. J. Dalton Trans. 2019, 48, 13212.

[24] Martínez-Hernández, C.; Benmansour, S.; Gómez García, C. J.
Polyhedron 2019, 170, 122.

[25] Taniguchi, K.; Chen, J.; Sekine, Y.; Miyasaka, H. Chem. Mater 2017, 29, 10053

[26] Martínez-Hernández, C.; Benmansour, S.; Gómez-García, C. J. Magnetochemistry 2019, 5, 34.

[27] Palacios-Corella, M.; Fernández-Espejo, A.; Bazaga-García, M.; Losilla, E. R.; Cabeza, A.; Clemente-León, M.; Coronado, E. Inorg. Chem. 2017, 56, 13865.

[28] Abhervé, A.; Mañas-Valero, S.; Clemente-León, M.; Coronado, E. Chem. Sci. 2015, 6, 4665.

[29] Abhervé, A.; Clemente-León, M.; Coronado, E.; Gómez-García, C. J.; Verneret, M. Inorg. Chem. 2014, 53, 12014.

[30] Gómez-Claramunt, P. Anilato-Based Multifunctional Molecular Materials, Ph. D. Dissertation, University of Valencia, Valencia, Spain, 2018.

[31] Benmansour, S.; Abhervé, A.; Gómez-Claramunt, P.; Vallés-García, C.; Gómez-García, C. J. ACS Appl. Mater. Interfaces 2017, 9, 26210.

[32] Sahadevan, S. A.; Abhervé, A.; Monni, N.; Sáenz, d. P.; GalánMascarós, J. R.; Waerenborgh, J. C.; Vieira, B. J. C.; AubanSenzier, P.; Pillet, S.; Bendeif, E.; Alemany, P.; Canadell, E.; Mercuri, M. L.; Avarvari, N. J. Am. Chem. Soc. 2018, 140, 12611.

Received December 1, 2019 Accepted December 27, 2019 